\title{
Long-Term Results of Cementless Total Hip Arthroplasty Using a Modular Stem in Patients with Femoral Head Osteonecrosis
}

\author{
Hyun-Ho Kim, MD ${ }^{1}$ Jung-Won Lim, MD ${ }^{1}$ Young-Bok Jung, MD ${ }^{2}$ Young-Kyun Lee, MD ${ }^{1}$ \\ Yong-Chan $\mathrm{Ha}, \mathrm{MD}^{1}$ Kyung-Hoi Koo, $\mathrm{MD}^{3}$
}

${ }^{1}$ Department of Orthopaedic Surgery, Chung-Ang University College of Medicine, Seoul, South Korea

2 Department of Orthopaedic Surgery, Joint Center, Hyundae General Hospital, Namyangju, Korea

${ }^{3}$ Department of Orthopaedic Surgery, Seoul National University Bundang Hospital, Seongnam, South Korea

Address for correspondence Yong-Chan Ha, MD, Department of Orthopaedic Surgery, Chung-Ang University College of Medicine, 102 Heukseok-ro, Dongjak-ku, Seoul 156-755, South Korea (e-mail: hayongch@naver.com).

J Hip Surg 2017;1:27-32.

\begin{abstract}
Keywords

- osteonecrosis

- cementless total hip arthroplasty

- S-ROM

Patients with femoral head osteonecrosis are younger and more active than those with osteoarthritis of the hip. More than 10-year results of total hip arthroplasty (THA) using modular cementless stem in osteonecrotic patients have not yet been reported. We determined clinical and radiologic results of cementless modular stem in a consecutive series of patients with femoral head osteonecrosis a minimum follow-up of 10 years. We retrospectively reviewed 48 patients (58 hips) who underwent THA for femoral head osteonecrosis with a cementless modular femoral stem. Metal-on-metal articulation was used in 32 hips and ceramic-on-ceramic articulation in 26 . There were 26 men and 22 women with a mean age of 52 years at the time of the operation. These patients were followed for 10 to 15 years. All of the acetabular cups and femoral stems had radiographic evidence of bone ingrown stability at the final follow-up. Three hips were revised due to infection. There were no revisions for ceramic fracture or adverse reaction to metal debris. The survival rate was $94.8 \%$ (95\% confidence interval: $89.8-$ $100 \%$ ). However, 12 patients ( 12 hips, $21 \%$ ) suffered thigh pain. In six patients (six hips), the pain disappeared within 1 to 2 years, whereas the pain persisted until the final followup in the remaining six patients. As of 10 to 15 year, radiologic results and survival of THA using a modular femoral stem were good in patients with osteonecrosis. However, the incidence of thigh pain remains a matter of concern.
\end{abstract}

Cementless modular stem was designed to allow the surgeon to independently match the anatomy of the metaphyseal and diaphyseal regions of the femoral canal of an individual patient. ${ }^{1}$ S-ROM stem (DePuy/Johnson \& Johnson), which has a hollow proximal sleeve and separate cylindrical core, was introduced in 1984. So far, long-term results of this prosthesis have been excellent in osteoarthritis, developmental dysplasia of hip, multiple epiphyseal dysplasia, and revision surgery. ${ }^{2-4}$ However, fretting and generation of metallic wear debris from the modular sleeve-stem junction and femoral stem-sleeve junction failure remain concerns. ${ }^{3,5}$ In addition, long-term results using this type of modular cementless femoral stem in patients with femoral head osteonecrosis has not yet been determined.

Femoral head osteonecrosis commonly occurs in younger adults than osteoarthritis of the hip. Total hip arthroplasty (THA) with use of traditional metal-on-polyethylene articulation in osteonecrotic patients was associated excessive wear, osteolysis, and early loosening. ${ }^{6}$ Since the late 1990 s, hard bearings (metal-on-metal and ceramic-on-ceramic bearings) have been used as alternatives to the metal-on-polyethylene articulation. ${ }^{7,8}$
Guest Editors: Lynne C. Jones, PhD and Michael A. Mont, MD
Copyright $\odot 2017$ by Thieme Medical Publishers, Inc., 333 Seventh Avenue, New York, NY 10001, USA. Tel: +1(212) 584-4662.
DOI http://dx.doi.org/ 10.1055/s-0036-1597966. ISSN 2472-8446. 
We report long-term results of THA with use of a cementless modular stem and hard bearings in a consecutive series of patients with femoral head osteonecrosis.

\section{Materials and Methods}

From January 1999 to December 2004, 65 patients (77 hips) underwent THA due to osteonecrosis of the femoral head using a cementless modular stem design with alumina-on-alumina or metal-on-metal articulation at author's hospital. Eight patients (10 hips) were lost to follow-up and nine patients (nine hips) died within 10 years after the index operation (-Fig. 1). Thus, the remaining 48 patients (58 hips) were followed for an average of 12.1 years (range: 10-15 years). There were 26 men and 22 women with a mean age of 51.4 years (range: 23-69 years) at the index arthroplasty. The mean weight was $63.8 \mathrm{~kg}$ (range: $43-83 \mathrm{~kg}$ ), the mean height was $164 \mathrm{~cm}$ (range: $148-179 \mathrm{~cm}$ ), and the mean body mass index was $23.7 \mathrm{~kg} / \mathrm{m}^{2}$ (range: $19.2-32.3 \mathrm{~kg} / \mathrm{m}^{2}$ ). The mean preoperative Harris hip score was 39 (range: $11-64$ ) points (- Table 1 ).

Two hemispherical titanium alloy cups and two bearing surfaces were used. In 32 hips, which were operated from January 1999 to December 2002, Ultima cup (DePuy/Johnson \& Johnson ) and a 28-mm metal-on-metal articulation, which was made of a cast cobalt-based Co-28Cr-6 Mo alloy with a carbon content of $>0.2 \%$ (high carbon), were used ( - Fig. 2). In

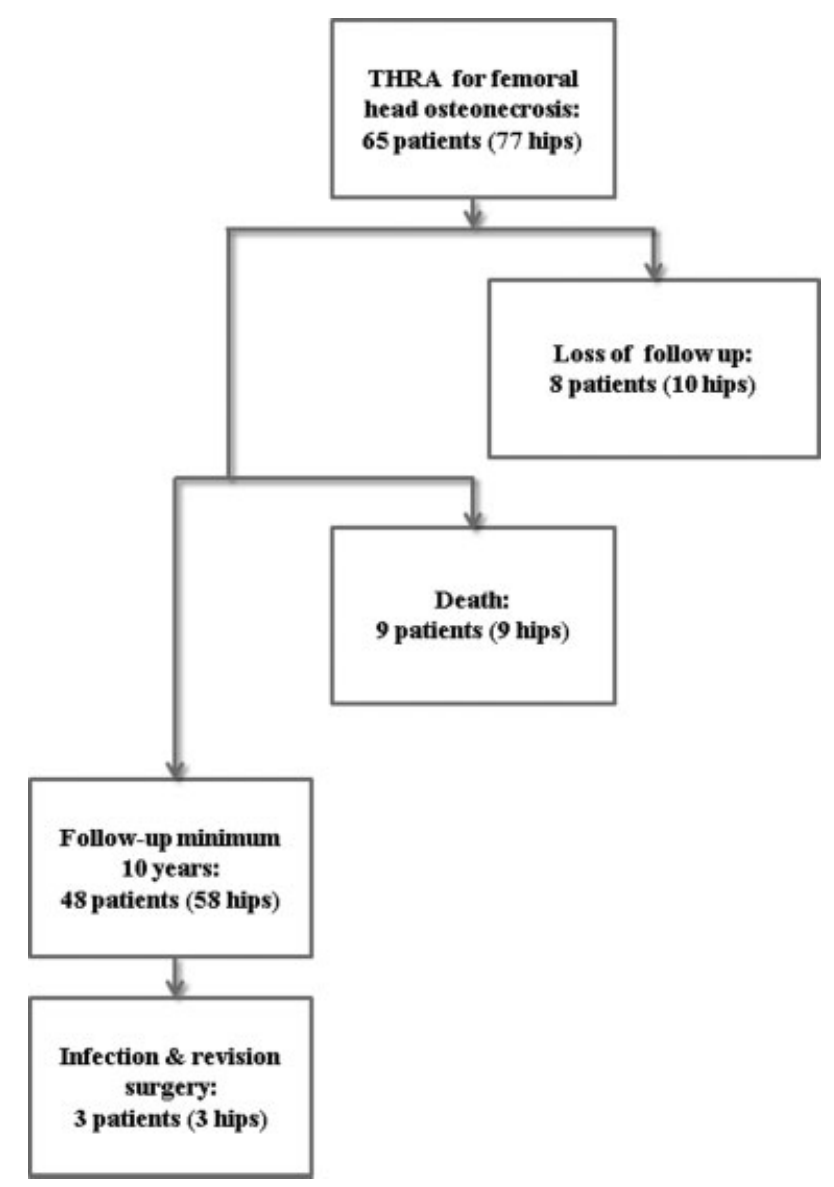

Fig. 1 Flow sheet of this study. THRA, total hip resurfacing arthroplasty.
Table 1 Demographic data

\begin{tabular}{|l|l|}
\hline $\begin{array}{l}\text { Number of patients } \\
\text { (hips) }\end{array}$ & 48 (58) \\
\hline Male:female & 26 (54\%):22(46\%) \\
\hline $\begin{array}{l}\text { Mean age (y) } \\
\text { Body mass index } \\
\text { (mean } \pm \text { SD) }\end{array}$ & $\begin{array}{l}51 \text { (range: } 23-69) \\
23.70 \pm 2.9 \\
\text { (range:19.2-32.3) }\end{array}$ \\
\hline Cause of osteonecrosis & \\
\hline Alcohol associated & 17 patients (20 hips) (35.4\%) \\
\hline Steroid induced & 13 patients (16 hips) (27.1\%) \\
\hline Posttraumatic & 3 patients (3 hips) (6.3\%) \\
\hline Idiopathic & 15 patients (19 hips) (31.3\%) \\
\hline Mean pre-op HHS & 39 (range: $11-64)$ \\
\hline Articulation & \\
\hline Metal on metal & 32 hips (55.2\%) \\
\hline Ceramic on ceramic & 26 hips (44.8\%) \\
\hline
\end{tabular}

Abbreviations: HHS, Harris Hip score; SD, standard deviation.

26 hips, which were operated from January 2002 to December 2004, Duraloc Option cup (DePuy/Johnson \& Johnson ) and a 28-mm alumina-on-alumina articulation (BIOLOX forte; CeramTec AG) were used ( - Fig. 3). S-ROM femoral stem was used in all hips. The stem was a proximally modular, cementless prosthesis that can be adjusted for altered proximal femoral anatomies by combining different sizes of stems and proximal sleeves. A porous-coated proximal sleeve couples to the central stem by means of a Morse taper lock. The central stem has a smooth polished finish with distal flutes to enhance initial fixation.

The study was approved by the institutional review board of our institution, which waved patient's informed consent.

All operations were performed by one senior surgeon using a posterolateral approach. All of the acetabular and femoral components were inserted with a press fit with adjunctive acetabular screws. Posterior capsules and short external rotators were routinely repaired.

Patients were mobilized on the second postoperative day and were instructed to walk with partial weight bearing with the aid of crutches for 4 weeks.

Routine follow-up visits were scheduled for 6 weeks, 3, 6, 9 , and 12 months, and yearly thereafter. Patients who did not return for regularly scheduled visits were contacted by telephone. Two nurses and a private locator found and visited nonresponders.

Clinical evaluation was performed using the Harris hip scoring system. ${ }^{9}$ The presence of thigh pain was reported by patients using a questionnaire and also asked to all patients at each follow-up. A diagnosis of thigh pain was made according to the definition by Barrack et al. ${ }^{10}$

The radiographic evaluation was completed by two independent observers who did not participate in the index operations. The 6 -week anteroposterior and cross-table lateral radiographs were considered to be the baseline for all comparisons. The abduction and anteversion of the acetabular component were measured on the 6-week radiographs. 


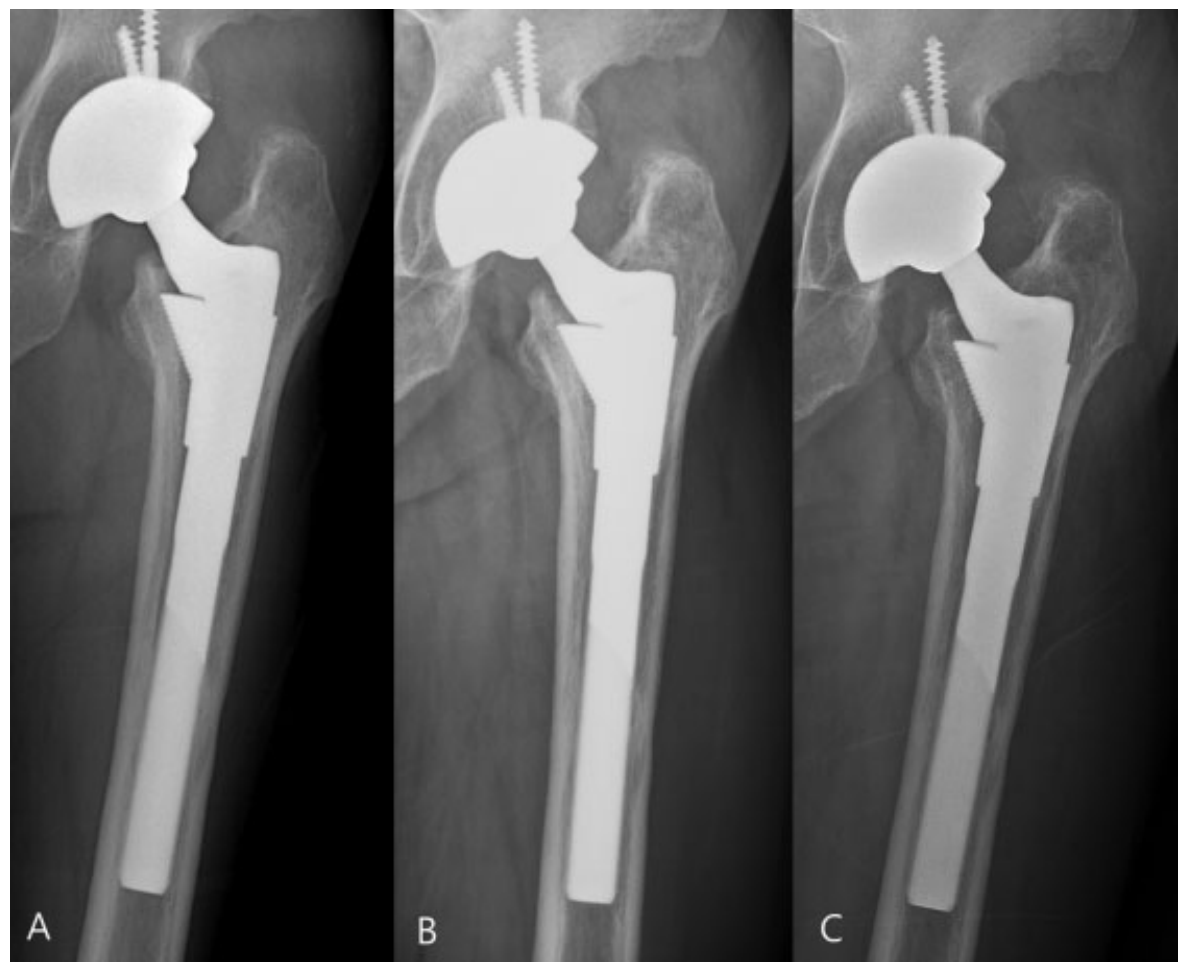

Fig. 2 A 56-year-old man underwent THA due to femoral head osteonecrosis with use of S-ROM femoral stem with metal on metal articulation. (A) An anteroposterior (AP) radiograph obtained 2 years postoperatively shows stable bone ingrowth in femur and acetabulum. AP radiograph shows well maintained without loosening or osteolysis at 5 (B) and 13 years (C) follow-up.

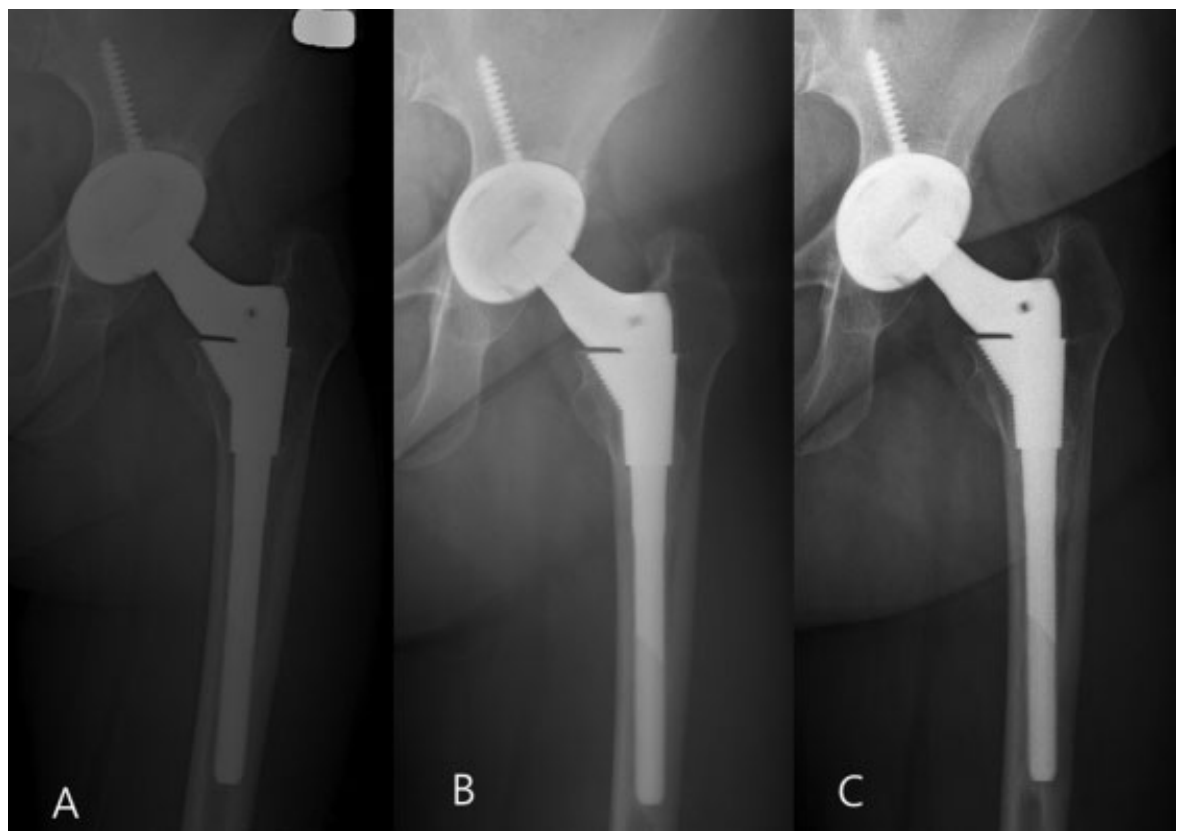

Fig. 3 A 31-year-old woman underwent THA due to femoral head osteonecrosis with use of S-ROM femoral stem with ceramic-on-ceramic articulation. (A) An anteroposterior (AP) radiograph obtained 1 year postoperatively shows stable bone ingrowth in femur and acetabulum. AP radiograph shows well maintained without loosening or osteolysis at 5 (B) and 12 years (C) follow-up.

Radiographic evaluation included an assessment of the fixation of the femoral and acetabular components, metal/ceramic components wear, osteolysis, and heterotopic ossification. Vertical migration of the acetabular component was measured along a perpendicular line from the hip center to the inter- teardrop line. Horizontal migration was assessed by measuring the distance from the teardrop to the intersection of the perpendicular line from the hip center and the inter-teardrop line. Acetabular components were considered loose if there was a change in alignment of $>4$-degrees or $\geq 4 \mathrm{~mm}$ of 
change in position. Femoral components were considered to be unstable when there was progressive subsidence exceeding $3 \mathrm{~mm}$, any change in position, a continuous radiolucent line wider than $2 \mathrm{~mm}$, widening of the femoral canal, or a large pedestal. ${ }^{11}$ The wear of articulation was calculated according to the method developed by Livermore et al. ${ }^{12}$ Osteolytic lesions were defined according to the criteria of Engh et al. ${ }^{13}$ The lesions were recorded according to the three zones described by DeLee and Charnley ${ }^{14}$ on the acetabular side and the seven zones described by Gruen et al ${ }^{15}$ on the femoral side. Heterotopic ossification was classified according to the system of Brooker et al. ${ }^{16}$

Kaplan-Meier survival analysis was performed for all hips with a mean 15 years follow-up with revision of either component as an endpoint. ${ }^{17}$ In subgroup analysis, comparison of clinical and radiologic results and Kaplan-Meier survivorship curves were completed of the implants between the metal-on-metal and ceramic-on-ceramic groups.

\section{Results}

\section{Complications}

A femoral crack occurred in eight hips during insertion of the stem, which was fixed with cerclage wire. The fractures healed and osseointegration of the prosthesis was achieved in all of them. One hip dislocated and was treated successfully with closed reduction and abduction brace for 3 months, after which there was no recurrence. Periprosthetic infection occurred in three hips: two hips with metal-on-metal bearing and one hip with ceramic-on-ceramic bearing at postoperative 1,2 , and 6 years, respectively. One patient received corticosteroid therapy for systemic lupus erythematosus and two were alcohol abusers. These three infections were treated with two-staged reconstruction: prostheses removal and insertion of an antibiotic-impregnated spacer at the first stage and implantation of new prosthesis at the second stage. All three infections were treated without an additional procedure. There were no clinically apparent deep venous thromboses or pulmonary emboli.

\section{Radiologic Evaluations}

All of the acetabular and femoral components had radiographic evidence of bone ingrowth at the last follow-up. Cortical thinning of the calcar femorale (zones 1 and 7 ), which was presumed to be due to cancellation of the cortical bone, was seen all 58 hips. The thinning was evident at 3 to 6 months postoperatively and was not progressive on serial radiographs. No acetabular osteolysis and no measurable wear were observed in any hip. There was no evidence of fretting and generation of metallic wear debris from the modular sleeve-stem junction at the latest follow-up.

Heterotopic ossification had developed in four hips (7\%): two grade I and two grade II ossifications.

\section{Clinical Evaluations}

The mean Harris hip score was 91 points (range: 64-100 points) at the final follow-up. Of the 58 hips, 47 had an excellent result, 8 had a good result, 2 had a fair result due to knee arthritis, and 1 had a poor result due to stroke.

Twelve patients (12 hips, $21 \%$ ) had a thigh pain. The pain occurred 6 months to 12 months after the arthroplasty. The median time of pain onset was postoperative 9 months. In six hips, the pain disappeared at 1 to 2 years during the followup. The duration of pain ranged 8 to 15 months (mean: 12 months). The remaining six patients (six hips, 10\%) had persistent thigh pain until the latest follow-up. The maximum visual analogue scale (VAS) score during the presence of thigh pain ranged 1 to 7 (mean: 4.3).

Two patients used walking support because of knee arthritis. There was no symptomatic adverse reaction to metal debris in metal-on-metal group and no ceramic fracture or squeaking on ceramic-on-ceramic group.

\section{Survivorship}

Kaplan-Meier survivorship analysis with any implant revision as the endpoint revealed a cumulative survival rate of 94.8\% (95\% confidence interval $[\mathrm{CI}]: 89.8-100 \%)$ at 15 years. There was no loosening of the stem and/or acetabulum in this series; the reason for revision was infection in all cases. In the worst-case scenario, assuming that the 14 hips lost to followup had a revision for any cause, the survival rate was $71.4 \%$ (95\% CI: 81.4-61.4\%) at 15 years (-Fig. 4).

There were no significant differences in clinical and radiologic results, and Kaplan-Meier survivorship of the implants were similar between the metal-on-metal and ceramic-onceramic groups (-Table $\mathbf{2}$ ).

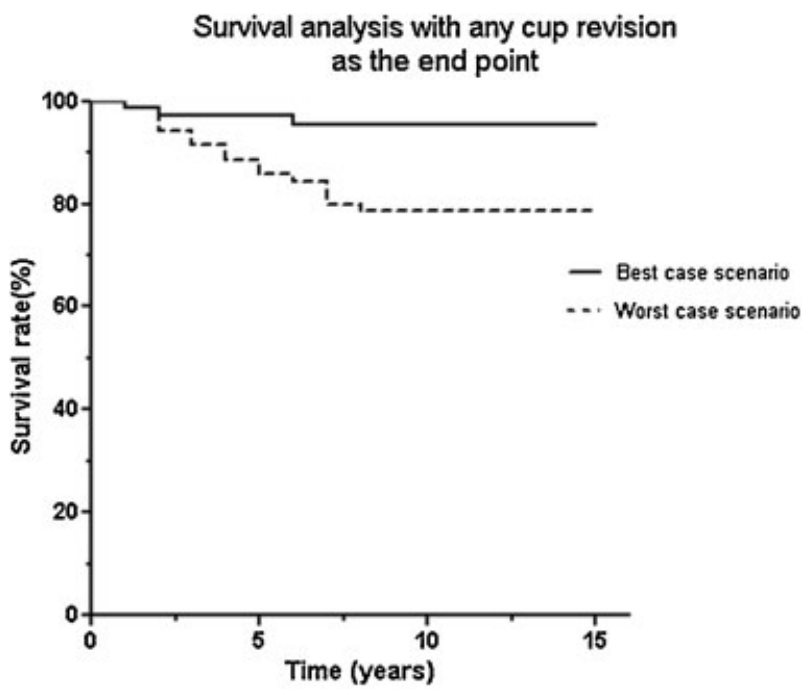

Fig. 4 The Kaplan-Meier survival curve including 95\% confidence interval $(\mathrm{Cl})$ estimates with implant revision as the endpoint. Excluding patients lost to follow-up (best-case scenario), there was only one failure of the femoral stem and survival probability was $94.8 \%$ (95\% Cl: $89.8-100 \%$ ) at 15 years (straight line). The dotted line shows the worstcase scenario presuming all 19 hips lost to follow-up and death failed and a cumulative survival rate was $71.4 \%(95 \% \mathrm{Cl}: 61.4-81.4 \%)$ at 15 years. 
Table 2 Comparison of demographics and outcomes between two groups

\begin{tabular}{|l|l|l|l|}
\hline Variable & Ceramic on ceramic & Metal on metal & $p$ Value \\
\hline Men:women (hips) & $12 / 14$ & $19 / 13$ & 0.315 \\
\hline Age (y) (mean \pm SD) & $49.5 \pm 12.9$ & $54 \pm 7.8$ & 0.125 \\
\hline Body mass index (kg/m $\left.{ }^{2}\right)$ & $24.1 \pm 3.8$ & $23.5 \pm 2.8$ & 0.187 \\
\hline Preoperative HHS (mean \pm SD) & $37 \pm 10.5$ & $40 \pm 8.1$ & 0.857 \\
\hline Postoperative HHS (mean \pm SD) & $90 \pm 7.5$ & $91 \pm 8.9$ & 0.285 \\
\hline Revision & 1 & 2 & 1.000 \\
\hline Kaplan-Meier survivorship (\%) & 96.2 & 93.8 & $12.1 \pm 2.8$ \\
\hline Follow-up (y) (mean \pm SD) & $10.6 \pm 2.0$ & 0.035 \\
\hline
\end{tabular}

Abbreviations: HHS, Harris hip score; SD, standard deviation.

\section{Discussion}

This is the first report on the minimal 10-year follow-up results after cementless modular THA in patients with femoral head osteonecrosis. The analysis addressed the issue of fretting and generation of metallic wear debris from the modular sleeve-stem junction at latest follow-up. No patient had symptomatic complications related with metal-debris. There was detectable wear, osteolysis or prosthetic loosening, and no failure at the stem-sleeve junction. The prosthesis survival rate was $94.8 \%$. However, 12 (21\%) patients suffered thigh pain.

The design of this cementless modular femoral stem is suitable to revision hip arthroplasty ${ }^{18}$ and primary THAs of hips with complex deformities of the proximal femur, such as developmental hip dysplasia, 2,19 hypoplastic proximal femur, ${ }^{4}$ and secondary arthritis due to multiple epiphyseal dysplasia. $^{20}$ The survivorship has been excellent, ranging from 93.3 to $100 \%$ at mid- to long-term follow-ups ${ }^{2-4,19,21}$ with variable survivorship of acetabular components according to the type of articulation (-Table 3 ).

In patients with osteonecrosis, THA poses a greater risk for complications and poor outcomes with increased rates of readmission and sepsis. ${ }^{22,23}$ However, another study, which utilized cementless THA and metal-on-metal articulation in 74 hips with osteonecrosis of the femoral head after kidney transplantation, reported a cumulative implant survivorship of $96.6 \%$ at a mean follow-up of 10.2 years. ${ }^{24}$

Thigh pain is a main factor of patient dissatisfaction. The reported incidence of thigh pain ranged from 3 to $25 \%$ after the use of cementless stems. ${ }^{10,25,26}$ It is associated with multiple factors including the stem design, size, elastic modulus, extent of porous coating of stem, and the architecture of the proximal femur in thigh pain. ${ }^{27,28}$ Stems with a cylindrical diaphyseal fit and large diameter have been associated with a high incidence of thigh pain than those with a tapered metaphyseal fit and small diameter, respectively. ${ }^{29,30}$

This study has several limitations. First, it was retrospective and performed in a small cohort, with lack of comparison with other diseases. Thus, we used a historical comparison with previously reported studies, ${ }^{6,8,21-24}$ which were presented in -Table 3. Second, among the 65 patients (77 hips), 9 patients (nine hips) died and 8 patients ( 10 hips) were lost before the 10-year minimum follow-up, leaving a followup rate of $64 \%$ at 10 to 15 years. The high rates of infection and death in our patients seemed related to causes of osteonecrosis including alcohol abuse and corticosteroid use, which might be potentially confounding comorbidities. ${ }^{8}$

Table 3 Comparison of study results using cementless modular femoral stem with variable articulations

\begin{tabular}{|c|c|c|c|c|c|c|c|}
\hline Authors & $\begin{array}{l}\text { Number of } \\
\text { hips/patient }\end{array}$ & $\begin{array}{l}\text { Mean } \\
\text { follow-up } \\
\text { (y) }\end{array}$ & $\begin{array}{l}\text { Cause of } \\
\text { diseases }\end{array}$ & $\begin{array}{l}\text { Survivorship/ } \\
\text { revision any } \\
\text { reason (\%) }\end{array}$ & $\begin{array}{l}\text { Survivorship/ } \\
\text { femur } \\
\text { revision (\%) }\end{array}$ & $\begin{array}{l}\text { Survivorship/ } \\
\text { acetabular } \\
\text { revision (\%) }\end{array}$ & Articulations \\
\hline Drexler et al ${ }^{4}$ & $30 / 25$ & 19 & $\begin{array}{l}\text { Hypoplastic } \\
\text { proximal femurs }\end{array}$ & NR & 93.3 & 61 & MOP \\
\hline Biant et $\mathrm{al}^{2}$ & $28 / 22$ & 10 & $\mathrm{DDH}$ & NR & 100 & 93 & MOP \\
\hline Kang et al ${ }^{19}$ & $45 / 42$ & 6.7 & Secondary OA & 100 & 100 & 100 & MOM or $\mathrm{COC}$ \\
\hline Christie et $\mathrm{al}^{3}$ & $175 / 159$ & 5.3 & $\begin{array}{l}\text { OA ,ON, } \\
\text { secondary OA }\end{array}$ & 98.3 & 99.4 & 98.9 & MOP \\
\hline Kim et $\mathrm{al}^{21}$ & $64 / 55$ & 15 & ON & NR & 93.8 & 78.1 & MOP \\
\hline Current study & $58 / 48$ & 12 & ON & 94.8 & 94.8 & 94.8 & MOM or COC \\
\hline
\end{tabular}

Abbreviations: COC, ceramic on ceramic; DDH, developmental dysplasia of hip; MOM, metal on metal; MOP, metal on polyethylene; NR, not reported; $\mathrm{OA}$, osteoarthritis; ON, osteonecrosis. 
In the current study, THA using cementless modular femoral stem with hard bearing articulations in patients with osteonecrosis yields good outcome without detectable wear, osteolysis, or loosening at a mean of 12 years follow-up with a survivorship of $94.8 \%$. Advances in tribology seem to extend the longevity of THA. However, surgeons should be aware of the high incidence of thigh pain when using a modular stem.

\section{Note}

Each author certifies that he or she has no commercial associations (e.g., consultancies, stock ownership, equity interest, patent/licensing arrangements, etc.) that might pose a conflict of interest in connection with the submitted article.

Each author certifies that his or her institution has approved the human protocol for this investigation, all investigations were conducted in conformity with ethical principles of research, and informed consent for participation in the study was obtained.

\section{References}

1 Cameron HU. Management of femoral deformities during the total hip replacement. Orthopedics 1996;19(9):745-746

2 Biant LC, Bruce WJ, Assini JB, Walker PM, Walsh WR. Primary total hip arthroplasty in severe developmental dysplasia of the hip. Ten-year results using a cementless modular stem. J Arthroplasty 2009;24(1):27-32

3 Christie MJ, DeBoer DK, Trick LW, et al. Primary total hip arthroplasty with use of the modular S-ROM prosthesis. Four to sevenyear clinical and radiographic results. J Bone Joint Surg Am 1999; 81(12):1707-1716

4 Drexler M, Dwyer T, Marmor M, et al. Nineteen year results of THA using modular $9 \mathrm{~mm}$ S-ROM femoral component in patients with small femoral canals. J Arthroplasty 2013;28(9): $1667-1670$

5 Mehran N, North T, Laker M. Failure of a modular hip implant at the stem-sleeve interface. Orthopedics 2013;36(7):e978-e981

6 Cornell CN, Salvati EA, Pellicci PM. Long-term follow-up of total hip replacement in patients with osteonecrosis. Orthop Clin North Am 1985;16(4):757-769

7 Kim YH, Choi Y, Kim JS. Cementless total hip arthroplasty with alumina-on-highly cross-linked polyethylene bearing in young patients with femoral head osteonecrosis. J Arthroplasty 2011; 26(2):218-223

8 Ha YC, Kim HJ, Kim SY, Kim TY, Koo KH. THA using an anatomic stem in patients with femoral head osteonecrosis. Clin Orthop Relat Res 2008;466(5):1141-1147

9 Harris WH. Traumatic arthritis of the hip after dislocation and acetabular fractures: treatment by mold arthroplasty. An endresult study using a new method of result evaluation. J Bone Joint Surg Am 1969;51(4):737-755

10 Barrack RL, Paprosky W, Butler RA, Palafox A, Szuszczewicz E, Myers L. Patients' perception of pain after total hip arthroplasty. J Arthroplasty 2000;15(5):590-596
11 Engh CA, Massin P, Suthers KE. Roentgenographic assessment of the biologic fixation of porous-surfaced femoral components. Clin Orthop Relat Res 1990;(257):107-128

12 Livermore J, Ilstrup D, Morrey B. Effect of femoral head size on wear of the polyethylene acetabular component. J Bone Joint Surg Am 1990;72(4):518-528

13 Engh CA, Hooten JP Jr, Zettl-Schaffer KF, et al. Porous-coated total hip replacement. Clin Orthop Relat Res 1994;(298):89-96

14 DeLee JG, Charnley J. Radiological demarcation of cemented sockets in total hip replacement. Clin Orthop Relat Res 1976;(121):20-32

15 Gruen TA, McNeice GM, Amstutz HC. "Modes of failure" of cemented stem-type femoral components: a radiographic analysis of loosening. Clin Orthop Relat Res 1979;(141):17-27

16 Brooker AF, Bowerman JW, Robinson RA, Riley LH Jr. Ectopic ossification following total hip replacement. Incidence and a method of classification. J Bone Joint Surg Am 1973;55(8):1629-1632

17 Kaplan EPM. Nonparametric estimation from incomplete observations. J Am Stat Assoc 1958;53:457-481

18 Imbuldeniya AM, Walter WK, Zicat BA, Walter WL. The S-ROM hydroxyapatite proximally-coated modular femoral stem in revision hip replacement: results of 397 hips at a minimum ten-year follow-up. Bone Joint J 2014;96-B(6):730-736

19 Kang JS, Moon KH, Kim RS, Park SR, Lee JS, Shin SH. Total hip arthroplasty using S-ROM prosthesis for dysplastic hip. Yonsei Med J 2011;52(4):655-660

20 Lim SJ, Park YS, Moon YW, Jung SM, Ha HC, Seo JG. Modular cementless total hip arthroplasty for multiple epiphyseal dysplasia. J Arthroplasty 2009;24(1):77-82

21 Kim SM, Lim SJ, Moon YW, Kim YT, Ko KR, Park YS. Cementless modular total hip arthroplasty in patients younger than fifty with femoral head osteonecrosis: minimum fifteen-year follow-up. J Arthroplasty 2013;28(3):504-509

22 Yang S, Halim AY, Werner BC, Gwathmey FW, Cui Q. Does osteonecrosis of the femoral head increase surgical and medical complication rates after total hip arthroplasty? A comprehensive analysis in the United States. Hip Int 2015;25(3):237-244

23 Stavrakis AI, SooHoo NF, Lieberman JR. A comparison of the incidence of complications following total hip arthroplasty in patients with or without osteonecrosis. J Arthroplasty 2015;30(1):114-117

24 Chang JS, Han DJ, Park SK, Sung JH, Ha YC. Cementless total hip arthroplasty in patients with osteonecrosis after kidney transplantation. J Arthroplasty 2013;28(5):824-827

25 Bourne RB, Rorabeck CH, Patterson JJ, Guerin J. Tapered titanium cementless total hip replacements: a 10- to 13-year followup study. Clin Orthop Relat Res 2001;(393):112-120

26 Lavernia C, D’apuzzo M, Hernandez VH, Lee DJ. Patient-perceived outcomes in thigh pain after primary arthroplasty of the hip. Clin Orthop Relat Res 2005;441(441):268-273

27 Engh CA, Bobyn JD, Glassman AH. Porous-coated hip replacement The factors governing bone ingrowth, stress shielding, and clinical results. J Bone Joint Surg Br 1987;69(1):45-55

28 Lavernia C, D'Apuzzo M, Hernandez V, Lee D. Thigh pain in primary total hip arthroplasty: the effects of elastic moduli. J Arthroplasty 2004;19(7, Suppl 2):10-16

29 Chen HH, Morrey BF, An KN, Luo ZP. Bone remodeling characteristics of a short-stemmed total hip replacement. J Arthroplasty 2009;24(6):945-950

30 Molli RG, Lombardi AV Jr, Berend KR, Adams JB, Sneller MA. A short tapered stem reduces intraoperative complications in primary total hip arthroplasty. Clin Orthop Relat Res 2012;470(2):450-461 